\title{
Review
}

\section{A Review of the Evidence for Treatment of Myocardial Infarction With Nonobstructive Coronary Arteries}

\author{
Shelby L. Sluchinski, RN, MN/NP Student, ${ }^{a}$ Edith Pituskin, RN, MN (NP Adult), PhD, ${ }^{a}$ \\ Kevin R. Bainey, MD, ${ }^{b}$ and Colleen M. Norris, RN, BScN, MN, PhD, GNP, FAHA ${ }^{\mathrm{a}}$ \\ ${ }^{a}$ Faculty of Nursing, University of Alberta, Edmonton, Alberta, Canada \\ ${ }^{b}$ Mazankowski Alberta Heart Institute, University of Alberta, Edmonton, Alberta, Canada
}

\begin{abstract}
Myocardial infarction (MI) with non-obstructive coronary arteries (MINOCA) is reported in $6 \%$ of patients with acute MI referred for catheterization. Because of the complex etiology and a limited amount of evidence, the treatment of MINOCA remains elusive. The etiology of MINOCA manifests from several causes including plaque disruption or erosion, epicardial coronary artery vasospasm, and coronary microvascular dysfunction. In addition, spontaneous coronary artery dissection, takotsubo, and myocarditis have been identified as contributing
\end{abstract}

Myocardial infarction (MI) with no obstructive coronary artery disease (MINOCA) has been reported in approximately $6 \%$ of patients with acute MI referred for catheterization. ${ }^{1}$ Because of the complex etiology and a limited amount of evidence, the treatment of MINOCA remains uncertain, posing a significant risk to patient outcomes. Most MIs involve $>50 \%$ obstruction when observed on coronary angiography, whereas MINOCA is an acute MI that involves $<50 \%$ blockage of the coronary arteries. ${ }^{2}$ These patients may experience typical MI-like symptoms such as shortness of breath and chest pain. ${ }^{3}$ Patients with MINOCA are most commonly young, non-white women with fewer traditional risk factors than those with MI involving coronary artery disease (CAD). Moreover, compared with men, recent studies report that women with MIs were 5 times more likely to have MINOCA with less favourable outcomes. ${ }^{4}$ Patients with MINOCA have none of the traditional indications for revascularization. ${ }^{5}$ Given health care providers' limited knowledge on MINOCA, patients are often falsely comforted with a promising

Received for publication January 8, 2020. Accepted March 30, 2020.

Ethics Statement: The research reported has adhered to the relevant ethical guidelines.

Corresponding author: Shelby L. Sluchinski, Faculty of Nursing, 5-246 Edmonton Clinic Health Academy, University of Alberta, Edmonton, Alberta T6G 1C9, Canada. Tel: +1-780-619-1253.

E-mail: ssluchin@ualberta.ca

See page 400 for disclosure information.

\section{RÉSUMÉ}

Un infarctus du myocarde (IM) à coronaires saines est signalé chez $6 \%$ des patients ayant subi un IM aigu orientés en cardiologie pour subir un cathétérisme. En raison de la complexité du tableau étiologique et de la rareté des données probantes, le traitement de I'IM à coronaires saines demeure insaisissable. L'IM à coronaires saines est attribuable à plusieurs causes, dont la rupture ou l'érosion de plaque, le vasospasme coronarien épicardique et la dysfonction microvasculaire coronarienne. De plus, la dissection spontanée de l'artère

prognosis. ${ }^{6}$ As a result, patients with MINOCA are less likely to receive secondary medical treatment, ${ }^{7}$ even though there is evidence that patients with MINOCA are likely to experience further coronary events. ${ }^{8}$ De Ferrari et al. ${ }^{7}$ reported that patients with MINOCA were less likely to receive aspirin (odds ratio [OR]: 0.31; confidence interval [CI]: 0.14-0.68), statins (OR: 0.31; CI: 0.17-0.58), angiotensin-converting enzyme inhibitor (ACEI)/angiotensin receptor blockers (ARB) (OR: 0.36; CI: 0.17-0.91), and beta-blockers (OR: 0.32; CI: 0.17-0.63) compared with those with CAD. Importantly, when comparing outcomes after a MINOCA with MICAD, both showed similar results in terms of cardiac arrest, decreased ejection fraction, heart failure, and length of hospital stay. ${ }^{4}$

It is now understood that the etiology of MINOCA manifests from several causes including plaque disruption? or erosion, ${ }^{10}$ epicardial coronary artery vasospasm, ${ }^{11}$ and coronary microvascular dysfunction. ${ }^{12}$ In addition, spontaneous coronary artery dissection (SCAD), ${ }^{13}$ takotsubo, ${ }^{14}$ and myocarditis ${ }^{15}$ are other factors that may play a role in the diagnosis of MINOCA. Identification of the underlying causes of MINOCA is needed to facilitate an accurate diagnosis, to optimize treatment, and to promote prevention of recurrent MIs. ${ }^{2}$ Cardiac MRI was found to be useful in providing a diagnosis in approximately $87 \%$ of cardiology cases. ${ }^{10}$ Other valuable tests include intravascular ultrasound, optical coherence tomography, and provocative testing for coronary vasospasm. ${ }^{17}$ Although it is more likely for an MI to occur with CAD, results from the 
to the diagnosis of MINOCA. Patients with MINOCA are frequently young, non-white females with fewer traditional risk factors compared with those with an $\mathrm{Ml}$ caused by obstructive coronary disease. Moreover, women who suffered an $\mathrm{Ml}$ are 5 times more likely to be diagnosed with MINOCA with a trend for worse outcomes compared with men. The increased recognition/diagnosis of MINOCA has highlighted a gap in our understanding of the treatment of MINOCA. This review identified that there is a paucity of evidence on treatment strategies for patients clinically diagnosed with MINOCA, but more importantly that MINOCA should be viewed as a "syndrome" with many different pathologic causes. This suggests that a standard protocol may not be useful for patients with MINOCA. Given the ongoing debate over the complexity of MINOCA, the main focus in the management of MINOCA should be to identify the underlying mechanism for targeted therapies that may optimize outcomes.
VIRGO trial highlight that MINOCA must remain one of the differential diagnoses. ${ }^{4}$ Given that patients with MINOCA have less than $50 \%$ coronary artery obstruction, ${ }^{2}$ treatments such as revascularization may not be an option, ${ }^{5}$ leaving both clinicians and patients with limited evidence-based therapies. There is a gap in the evidence on the treatment of MINOCA. Therefore, the purpose of this review was to identify the evidence on the treatment of MINOCA.

\section{Material and Methods}

A comprehensive review of the literature on the treatment of MINOCA was conducted. A University of Alberta librarian was consulted to assist in finding appropriate articles to provide a critical analysis of the literature. Although the aim was to focus on randomized controlled trials (RCTs) on the treatment of MINOCA, outcomes of the review protocol failed to identify any RCTs investigating the treatment of MINOCA. As a result, all research designs were included to ascertain the current research on the treatment of MINOCA. The search strategy is outlined in Table 1. Inclusion criteria consisted of English peerreviewed manuscripts published in the last 5 years (20142019), with older articles used as supporting evidence to these studies.

A total of 530 articles were found using the databases MEDLINE, EMBASE, and CINAHL. See Figure 1 for a flow diagram for the selection process. The titles and abstracts were reviewed for suitable articles that focused on the treatment of MINOCA. Nine manuscripts were selected for full-text review based on their relevance to the research question. Finally, 4 manuscripts provided evidence on treatments for patients with MINOCA. See Table 2 for a further selection process. Reference lists of the articles were scanned, and a number of articles were consulted for supporting evidence. coronaire, le syndrome de takotsubo et la myocardite contribuent notoirement au diagnostic de I'IM à coronaires saines. L'IM à coronaires saines survient souvent chez de jeunes femmes non blanches présentant moins de facteurs de risque classiques que les sujets victimes d'un IM causé par une coronaropathie obstructive. Par ailleurs, la probabilité d'un diagnostic d'IM à coronaires saines est cinq fois plus élevée chez les femmes ayant subi un IM, et l'issue de la maladie tend à être pire que chez les hommes. La reconnaissance accrue et le diagnostic plus fréquent de I'IM à coronaires saines révèlent une lacune dans notre compréhension du traitement de cette cardiopathie. Le présent article de synthèse met en lumière le manque de données probantes visant les stratégies thérapeutiques à mettre en œuvre dans les cas d'IM à coronaires saines diagnostiqués cliniquement. Surtout, il témoigne du fait que I'IM à coronaires saines doit être considéré comme un "syndrome " aux causes pathologiques nombreuses et variées. Le portrait qui s'en dégage donne à penser qu'un protocole standard peut ne pas être utile chez les patients ayant subi un IM à coronaires saines. L'IM à coronaires saines étant l'objet d'un débat incessant en raison de sa complexité, sa prise en charge devrait principalement viser à en cerner le mécanisme sous-jacent pour permettre la mise en œuvre de thérapies ciblées susceptibles d'optimiser les résultats cliniques.

\section{Results}

The 4 studies addressing treatment for MINOCA included 1 observational study comprising patients in the Swedish Web-system for Enhancement and Development of Evidencebased care in Heart disease Evaluated According to Recommended Therapy (SWEDEHEART registry), ${ }^{18} 2$ registrybased cohort studies, ${ }^{19,20}$ and 1 American Heart Association (AHA) scientific statement. ${ }^{21}$ Three of the studies were conducted in Europe, specifically in the United Kingdom ${ }^{20}$ and Sweden, ${ }^{18,19}$ both of which used SWEDEHEART registry. The AHA scientific statement was completed through the American Heart Association Science Advisory and coordinating committee.

All studies included shared the definition of MINOCA as an MI with $<50 \%$ obstruction on coronary angiography. ${ }^{2}$ Table 3 summarizes study-based treatments and recommendations. The medications used within the studies included metoprolol, ACEI or ARB, statins, and dual antiplatelet therapy (DAPT). One study also included cardiac rehabilitation as treatment (follow-up secondary prevention) for MINOCA. ${ }^{19}$ Two of the studies reported on the reduction of major adverse cardiovascular events (MACE) events using statins when treating MINOCA. ${ }^{18,19}$ ACEI/ARBs were also reported as significantly associated with decreased 6-month mortality and decreased number of MACE events. ${ }^{18,20}$ Betablocker use was significantly associated with lower MACE events in one study that restricted the sample to patients with MINOCA $;{ }^{18}$ however, no significant association between beta-blocker use and 6-month mortality was demonstrated in a cohort comparing patients with MINOCA with those with an MICAD. ${ }^{20}$ Lindahl et al. ${ }^{18}$ demonstrated no significant reduction in MACE with DAPT use. Cardiac rehabilitation was reported to have positive effects on the treatment of MINOCA. ${ }^{20}$

The largest study on the treatment of MINOCA, with a sample size of 9136 patients with MINOCA, was an observational study collected from the SWEDEHEART registry. 
Table 1. Search strategy

\begin{tabular}{ll}
\hline \hline Database & Date searche \\
\hline $\begin{array}{l}\text { Ovid MEDLINE(R) and Epub ahead } \\
\text { of print, in-process, and other }\end{array}$ & July 2, 2019 \\
nonindexed citations and daily & \\
$<1946$ to June 26, 2019> &
\end{tabular}

Embase $<1974$ to 2019 June $26>$

CINAHL
July 2, 2019 S1. minoca or "myocardial infarction with non-obstructive coronary artery" or "myocardial infarction

S1. minoca or "myocardial infarction with non-obstructive coronary artery" or "myocardial infarctio
with nonobstructive coronary artery" or "myocardial infarction with non-obstructive coronary arteries" or "myocardial infarction with nonobstructive coronary arteries" or ACSNNOCA or ("Acute coronary syndrome*" and (normal near/3 angiograph* or "non-obstructive" or nonobstructive))

S2. (MH "Myocardial Infarction+") or infarction or MI or "heart attack"

S3. ("without" or "no" or absen*) w2 (coronary or arter*) w2 obstruct* or (nonobstructive or nonobstructive or un-obstruct* or unobstruct* or "no obstruct*" or "no flow limiting") w3 ("coronary arter*" or cad) or (normal w2 angiograph*) or ("without" or "no" or absen* or moderate) w2 (stenos* or lesion*)

S4. S2 AND S3

S5. $\mathrm{S} 1$ or $\mathrm{S} 4$

S6. (MH "Disease Management") OR (MH "Treatment Outcomes+") or SU (dh or dt or nu or pc or $\mathrm{rt}$ or $\mathrm{rh}$ or su or th) or (treat* or manag* or therap* or intervention*)

S7. S5 AND S6
The results over a mean of 4.1 years in patients with MINOCA showed a $23 \%$ reduction in MACE when taking statins, $18 \%$ reduction with $\mathrm{ACEI}$ or $\mathrm{ARB}$, and $14 \%$ reduction with metoprolol (beta-blocker). There was no significant MACE reduction with DAPT. ${ }^{18}$ Eggers et al. ${ }^{19}$ also used cases from the SWEDEHEART registry, using a sample size of 5830 patients with MINOCA. In this registry-based cohort study, patients with MINOCA were followed up after 6-10 weeks and 1 year after MI. Results demonstrated a 10\%-23\% reduction in MACE when participating in cardiac rehabilitation involving exercise and a $24 \%-32 \%$ reduction in MACE when therapeutic ranges of low-density lipoprotein cholesterol levels were achieved, such as after the use of statins. Manfrini et al., ${ }^{20}$ using data from the Evaluation of Methods and Management of Acute Coronary Events registry (350 patients with MINOCA), reported that ACEI had a positive effect in 


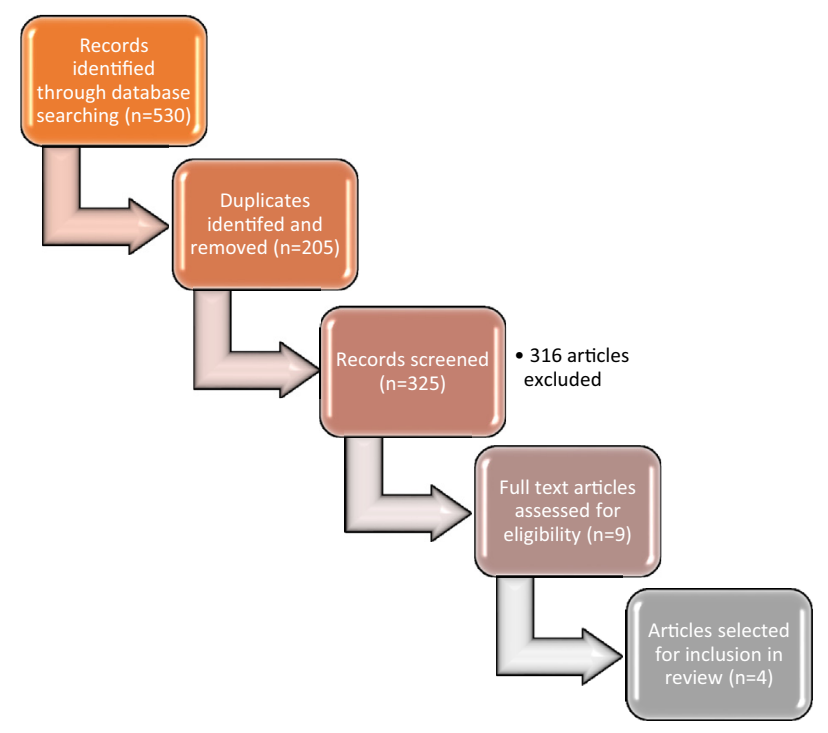

Figure 1. Flow diagram for the review selection process.

reducing mortality 6 months after MI; however, beta-blockers had a neutral effect. They surmised that the neutral effect of metoprolol could have been due to the smaller sample size.

For the purposes of this review it was determined that the recent AHA scientific statement on the diagnosis and management of patients with MINOCA met the inclusion criteria. While presenting a standard management strategy for patients with MINOCA, including consideration of the following: (1) emergency supportive care; (2) a working diagnosis approach for patient evaluation; (3) cardioprotective therapies irrespective of the cause of the MINOCA; and (4) cause-targeted therapies, ${ }^{21}$ the statement suggests that specific therapies to treat the underlying cause of MINOCA should be considered in addition to known cardioprotective therapies, lifestyle changes, and cardiac rehabilitation.

The AHA statement focuses primarily on the evidence of cause-targeted therapies in the overall treatment of MINOCA, specifically for MINOCA with ischemic presentation. This includes aspirin as the main initial treatment for plaque rupture and erosion. ${ }^{22}$ Although the treatment for coronary microvascular dysfunction is limited, there is evidence of a reduction of symptoms when using calcium channel blockers and beta-blockers. ${ }^{23}$ There are currently no RCTs on the treatment of SCAD, but one observational study recommends the use of beta-blockers. ${ }^{24}$ It was noted that the use of DAPT for patients with SCAD is controversial due to the increased risk for bleeding. ${ }^{21}$ However, one study reported that the use

Table 2. Reason for exclusion of 5 manuscripts from 9 selected for full review

\begin{tabular}{lll}
\hline \hline Number of articles & \multicolumn{1}{c}{ Reason for exclusion } & \multicolumn{1}{c}{ References } \\
\hline 3 & $\begin{array}{l}\text { Focused only on the treatment of } \\
\text { coronary spasm }\end{array}$ & $\begin{array}{l}\text { Ishii et al. } \\
\text { Ishii et al. }\end{array}$ \\
Piao et al. ${ }^{36}$ \\
Adatia et al. ${ }^{37}$ \\
1 & $\begin{array}{l}\text { Focused on the likelihood of patients } \\
\text { receiving medications rather than } \\
\text { the effect of treatment itself }\end{array}$ & Article is a short editorial \\
\hline
\end{tabular}

of clopidogrel in patients with SCAD was reasonable, if the intimal tear was prothrombotic. ${ }^{25}$ Importantly, it was noted that a conservative approach for treatment is necessary for patients with MINOCA caused by SCAD as cardiac intervention or stenting could exacerbate the dissection. ${ }^{26}$ Reporting on a cohort study that included 72 patients with takotsubo, Abanador-Kamper et al. ${ }^{27}$ suggest that patients might benefit from antithrombotic and heart failure therapies for the first 2 months after event. Recovery after myocarditis ranges anywhere from spontaneous resolution without specific treatment in mild cases, ${ }^{28}$ to the need for heart failure treatment in more severe cases. ${ }^{29}$ Finally, based on an RCT from 1993 that provides evidence for the suppression of anginal symptoms, Tamis-Holland et al. ${ }^{21}$ report that the cornerstone therapy for patients with epicardial coronary artery vasospasm is calcium channel blockers. ${ }^{30}$

\section{Discussion}

This review identified that there is presently a paucity of high-level evidence on treatment strategies for patients clinically diagnosed with MINOCA. More importantly, it further highlights the fact that MINOCA should be viewed as a "syndrome" with many different pathologic causes. ${ }^{21}$ Focusing on the clinical diagnosis of MINOCA as a single entity may in fact jeopardize patient care and safety. For example, a conservative approach for treatment is necessary for patients with MINOCA caused by SCAD as cardiac intervention or stenting has been reported to exacerbate the dissection. ${ }^{26}$ Identification of the underlying cause of MINOCA is needed to effectively treat the MINOCA population. ${ }^{18}$

Based on the results of retrospective cohort/registry studies including those contained in this review, use of reninangiotensin system blockers and beta-blockers is associated with lower mortality in patients with MINOCA. ${ }^{18,31}$ Moving forward, the current MINOCA BAT Randomized Evaluation of beta-Blocker and ACEI/ARB Treatment in MINOCA Patients (ClinicalTrials.gov Identifier: NCT03686696) will randomize 3500 patients with MINOCA to treatment with ACEIs/ARBs and beta-blockers or matching placebo. The primary end point of the study is time to death of any cause or readmission due to MACE and should provide valuable data on the benefits or risks of routine cardioprotective therapies in patients with MINOCA. However, based on this review and highlighted by the scientific statement from the American Heart Association on MINOCA, ${ }^{21}$ it is important that clinicians use an individualized approach to the management of patients with MINOCA based on the underlying cause. ${ }^{32}$ MINOCA involves many subtypes, suggesting that a standard protocol, such as those established for patients with MICAD, may not be as useful for patients with MINOCA. ${ }^{4}$ Given the ongoing debate over the complexity of MINOCA, treatment strategies could likely benefit from categorizing and treating more specific subsets of patients. ${ }^{33}$ The main focus in the management of MINOCA is to identify the underlying mechanism for targeted therapies and optimize outcomes. For now, although awaiting the results of prospective randomized data, this review suggests that there are cohort-level data supporting improved outcomes after the administration of ACEIs/ARBs, statins, and cardiac rehabilitation when treating 
Table 3. Summary of selected articles and recommended treatment

\begin{tabular}{|c|c|c|c|c|}
\hline Author & Type of study & MINOCA sample size & Results & Recommended treatment \\
\hline Lindahl et al., $2017^{18}$ & Observational Registry Study & 9136 patients with MINOCA & $\begin{array}{l}\text { The hazard ratios }(95 \% \text { confidence intervals) } \\
\text { for MACE events between propensity } \\
\text { matched treated and untreated patient with } \\
\text { MINOCA were: statins, } 0.77(0.68-0.87) \text {, } \\
\text { ACEIs/ARBs } 0.82(0.73-0.93) \text { and } 0.86 \\
(0.74-1.01) \text { in patients on beta-blockers. For } \\
\text { patients on DAPT followed for } 1 \text { y, the } \\
\text { hazard ratio was nonsign } 0.90(0.74-1.08)\end{array}$ & $\begin{array}{l}\text { Metoprolol, ACEI/ARBs, statins, not } \\
\text { DAPT }\end{array}$ \\
\hline Eggers et al., $2018^{19}$ & Registry-based Cohort Study & $\begin{array}{l}5830 \text { patients with MINOCA vs } \\
54,637 \text { with MI with obstructive } \\
\text { coronary disease (MIOCA) }\end{array}$ & $\begin{array}{l}\text { Patients with MINOCA followed up less and } \\
\text { were less likely to achieve any of the } \\
\text { secondary prevention targets compared with } \\
\text { patients with MIOCA. Participation in the } \\
6 \text { - to } 10 \text {-wk follow-up was associated with a } \\
3 \%-20 \% \text { risk reduction in MINOCA, } \\
\text { similar to MIOCA. The improvement in } \\
\text { outcome in the MINOCA group was } \\
\text { mainly mediated by achieving target range } \\
\text { low-density lipoprotein cholesterol levels } \\
\text { (24\%-32\% risk reduction) and, to a smaller } \\
\text { extent, by participation in exercise training } \\
\text { (10\%-23\% risk reduction) }\end{array}$ & Statins, cardiovascular rehabilitation \\
\hline Manfrini et al., $2014^{20}$ & Registry-based Cohort Study & $\begin{array}{l}350 \text { patients with MINOCA vs } 1602 \\
\text { with MIOCA }\end{array}$ & $\begin{array}{l}\text { In patients with MINOCA, ACEI therapy was } \\
\text { associated with a lower } 6 \text {-mo mortality (OR: } \\
0.31 ; 95 \% \text { CI, } 0.03-0.78, P=0.004 \text { ). No } \\
\text { significant association between beta-blocker } \\
\text { use and death }\end{array}$ & ACEI, neutral effect of metoprolol \\
\hline Tamis-Holland et al., $2019^{21}$ & AHA scientific guidelines & & $\begin{array}{l}\text { Patients should be treated according to their } \\
\text { underlying etiology of MINOCA }\end{array}$ & $\begin{array}{l}\text { Plaque rupture and erosion }=\text { aspirin } \\
\text { for initial treatment } \\
\text { Epicardial coronary artery vasospasm }= \\
\text { CCB } \\
\text { CMD }=\text { CCB and beta-blockers } \\
\text { SCAD = beta-blockers, clopidogrel }\end{array}$ \\
\hline
\end{tabular}

ACEI, angiotensin converting enzyme inhibitor; AHA, American Heart Association; ARB, angiotensin receptor blocker; CCB, calcium channel blocker; CI, confidence interval; CMD, coronary microvascular dysfunction; DAPT, dual antiplatelet therapy; MACE, major adverse cardiovascular events; MINOCA, MI with $<50 \%$ obstruction on coronary angiography; OR, odds ratio; SCAD, spontaneous coronary artery dissection. 
patients with MINOCA. However, nonsignificant hazard ratios suggest that the use of DAPT must include patientspecific risk/benefit assessments. Finally, results have demonstrated increased risk of worse outcomes after revascularization in particular subsets of patients with MINOCA (SCAD).

\section{Conclusion}

MINOCA is an umbrella term for patients who present with an MI with no CAD that encompasses a variety of cardiac etiology. A review of the treatment strategies for patients with MINOCA suggests that the main focus in the management of MINOCA is to identify the underlying mechanism for targeted therapies and optimize outcomes. Although MINOCA cohort studies have identified benefits to patients using recognized therapies for the treatment of MICAD, the quality of the evidence is low. Until RCT data are available, patient-centered evaluation of treatment benefit, harms, and burden are essential.

\section{Funding Sources}

Funding for this research was provided by the Faculty of Nursing, University of Alberta-Research Assistantship.

\section{Disclosures}

C.M.N. is funded in part by the Cardiovascular Health \& Stroke Strategic Clinical Network-Alberta Health Services. The other authors have no conflicts of interest to disclose.

\section{References}

1. Pasupathy S, Air T, Dryer RP, Tavella R, Beltrame JF. Systematic review of patients presenting with suspected myocardial infarction and nonobstructive coronary arteries. Circulation 2015;131:861-70.

2. Agewall S, Beltrame JF, Reynolds HR, et al. ESC working group position paper on myocardial infarction with non-obstructive coronary arteries. Eur Heart J 2017;38:143-53.

3. Bhatt DL. An unusual type of heart attack. Harvard Heart Letter 2018;29:2.

4. Safdar B, Spatz ES, Dreyer RP, et al. Presentation, clinical profile, and prognosis of young patients with myocardial infarction with nonobstructive coronary arteries (MINOCA): results from the VIRGO study. J Am Heart Assoc 2018;7:1-22.

5. Roe MT, Harrington RA, Prosper DM, et al. Clinical and therapeutic profile of patients presenting with acute coronary syndromes who do not have significant coronary artery disease. The platelet glycoprotein IIb/IIIa in unstable angina: receptor suppression using integrilin therapy (PURSUIT) trial investigators. Circulation 2000;102:1101-6.

6. De Ferrari GM, Fox KA, White JA, et al. Outcomes among non-STsegment elevation acute coronary syndromes patients with no angiographically obstructive coronary artery disease: observations from 37,101 patients. Eur Heart J 2014;3:37-45.

7. De Ferrari GM, Leonardi S, Baduena L, et al. Patients with acute coronary syndrome and non-obstructive coronary disease in the real world are markedly undertreated. J Cardiovasc Med 2011;12:700-8.

8. Dey S, Flather MD, Devlin G, et al. Global registry of acute coronary events investigators. Sex-related differences in the presentation, treatment and outcomes among patients with acute coronary syndromes. Heart 2009;95:20-6.
9. Iqbal SN, Feit F, Mancini GBJ, et al. Characteristics of plaque disruption by intravascular ultrasound in women presenting with myocardial infarction without obstructive coronary artery disease. Am Heart J 2014;167:715-22.

10. Ferrante G, Nakano M, Prati F, et al. High levels of systemic myeloperoxidase are associated with coronary plaque erosion in patients with acute coronary syndromes: a clinicopathological study. Circulation 2010;122:2505-13.

11. Ong P, Athanasiadis A, Borgulya G, Voehringer M, Sechtem U. 3-year follow-up of patients with coronary artery spasm as cause of acute coronary syndrome: the CASPAR (coronary artery spasm in patients with acute coronary syndrome) study follow-up. J Am Coll Cardiol 2011;57: $147-52$.

12. Lanza GA, Crea F. Primary coronary microvascular dysfunction: clinical presentation, pathophysiology, and management. Circulation 2010;121: 2317-25.

13. Saw J, Humphries K, Aymong E, et al. Spontaneous coronary artery dissection: clinical outcomes and risk of recurrence. J Am Coll Cardiol 2017:70:1148-58.

14. Pelliccia F, Parodi G, Greco C, et al. Comorbidities frequency in takotsubo syndrome: an international collaborative systematic review including 1109 patients. Am J Med 2015;128:654.e11-9.

15. Tornvall P, Gerbaud E, Behaghel A, et al. Myocarditis or "true" infarction by cardiac magnetic resonance in patients with a clinical diagnosis of myocardial infarction without obstructive coronary disease: a metaanalysis of individual patient data. Atherosclerosis 2015;241:87-91.

16. Pathik B, Raman B, Mohd Amin NH, et al. Troponin-positive chest pain with unobstructed coronary arteries: incremental diagnostic value of cardiovascular magnetic resonance imaging. Eur Heart J Cardiovascular Imaging 2016;17:1146-52.

17. Tamis-Holland JE, Jneid H. Myocardial infarction with nonobstructive coronary arteries (MINOCA): it's time to face reality! J Am Heart Assoc $2018 ; 7: 1-4$

18. Lindahl B, Baron T, Erlinge D, et al. Medical therapy for secondary prevention and long-term outcome in patients with myocardial infarction with nonobstructive coronary artery disease. Circulation 2017;135: 1481-9.

19. Eggers KM, Hadziosmanovic N, Baron T, et al. Myocardial infarction with nonobstructive coronary arteries: the importance of achieving secondary prevention targets. Am J Med 2018;131. 524-31.e6.

20. Manfrini O, Morrell C, Das R, et al. Effects of angiotensin-converting enzyme inhibitors and beta blockers on clinical outcomes in patients with and without coronary artery obstructions at angiography (from a Register-Based Cohort Study on Acute Coronary Syndromes). Am J Cardiol 2014;113:1628-33.

21. Tamis-Holland JE, Jneid H, Reynolds HR, et al. Contemporary diagnosis and management of patients with myocardial infarction in the absence of obstructive coronary artery disease: a scientific statement from the American heart association. Circulation 2019;139:e891-908.

22. Amsterdam EA, Wenger NK, Brindis RG, et al. AHA/ACC guideline for the management of patients with non-ST-elevation acute coronary syndromes: a report of the American College of Cardiology/American Heart Association Task Force on Practice Guidelines. Circulation 2014;130: e344-426.

23. Beltrame JF, Crea F, Camici P. Advances in coronary microvascular dysfunction. Heart Lung Circ 2009;18:19-27.

24. Mahmoud AN, Taduru SS, Mentias A, et al. Trends of incidence, clinical presentation, and in-hospital mortality among women with acute 
myocardial infarction with or without spontaneous coronary artery dissection: a population-based analysis. JACC Cardiovasc Interv 2018;11:80-90.

25. Saw J, Mancini GBJ, Humphries K. Contemporary review on spontaneous coronary artery dissection. J Am Coll Cardiol 2016;68:297-312.

26. Tweet MS, Hayes SN, Pitta SR, et al. Clinical features, management and prognosis of spontaneous coronary artery dissection. Circulation 2012;126:579-88.

27. Abanador-Kamper N, Kamper L, Wolfertz J, et al. Evaluation of therapy management and outcome in takotsubo syndrome. BMC Cardiovasc Disord 2017;17:1-9.

28. Caforio AL, Calabrese F, Angelini A, et al. A prospective study of biopsyproven myocarditis: prognostic relevance of clinical and aetiopathogenic features at diagnosis. Eur Heart J 2007;28:1326-33.

29. Yancy CW, Jessup M, Bozurkt B, et al. 2013 ACCF/AHA guideline for the management of heart failure: a report of the American College of Cardiology Foundation/American Heart Association Task Force on Practice Guidelines. J Am Coll Cardiol 2013;62:147-239.

30. Chahine RA, Feldman RL, Giles TD, et al. Randomized placebocontrolled trial of amlodipine in vasospastic angina. J Am Coll Cardiol 1993;21:1365-70.
31. Choo EH, Chang K, Lee KY, et al. Prognosis and predictors of mortality in patients suffering myocardial infarction with non-obstructive coronary arteries. J Am Heart Assoc 2019;8:e0011990.

32. Mukherjee D. Myocardial infarction with nonobstructive coronary arteries: a call for individualized treatment. J Am Heart Assoc 2019;8: e013361.

33. Bainey KR, Welsh RC, Alemayehu W, et al. Population-level incidence and outcomes of myocardial infarction with non-obstructive coronary arteries (MINOCA): insights from the Alberta contemporary acute coronary syndrome patients invasive treatment strategies (COAPT) study. Int J Cardiol 2018;264:12-7.

34. Ishii M, Kaikita K, Sato K, et al. Impact of aspirin on the prognosis in patients with coronary spasm without significant atherosclerotic stenosis. Int J Cardiol 2016;220:328-32.

35. Ishii M, Kaikita K, Sato K, et al. Impact of statin therapy on clinical outcome in patients with coronary spasm. J Am Heart Assoc 2016;5:1.

36. Piao ZH, Jeong MH, Li Y, et al. Benefit of statin therapy in patients with coronary spasm-induced acute myocardial infarction. J Cardiol 2016;68: 7-12.

37. Adatia F, Galway S, Grubisic M, et al. Cardiac medication use in patients with acute myocardial infarction and nonobstructive coronary artery disease. J Womens Health 2017;26:1185-92. 